\title{
Solvent Effect on the Fluorescence Properties of Two Biologically Active Thiophene Carboxamido Molecules
}

\author{
D Nagaraja, ${ }^{*}$ H S Geethanjali, ${ }^{\dagger}$ N R Patil, $\neq$ \\ F M Sanningannavar§, R A Kusanur ** and R M Melavanki††
}

\begin{abstract}
The absorption and fluorescence spectra of two thiophene carboxamido molecules namely $2-\left(3^{\prime}, 4^{\prime}, 5^{\prime}\right.$ - trimethoxy phenyl) imino-3-N-ethylcarboxamido-4, 5, tetramethylene thiophene $(\boldsymbol{X})$ and $2-\left(4^{\prime}-\mathrm{N}, \quad \mathrm{N}-\right.$ dimethylaminophenyl) imino-3-(N-2' methylphenyl carboxamido)-4, 5, tetramethylene thiophene $(\mathbf{Y})$ have been recorded at room temperature. The ground $\left(\mu_{\mathrm{g}}\right)$ and excited $\left(\mu_{\mathrm{e}}\right)$ state dipole moments are estimated from Lippert, Bakhshiev, Kawski-Chamma-
\end{abstract}

* Department of Physics, Bangalore Institute of Technology, Bangalore560004, Karnataka, India

† Department of Physics, Bangalore Institute of Technology, Bangalore560004, Karnataka, India

‡ Department of Physics, B V B College of Engineering and Technology, Hubli-580031, Karnataka, India

$\S$ Department of Physics, Karnatak Science College Dharwad-580003, Karnataka, India

** Department of Chemistry, R. V. College of Engineering, Bangalore560059, Karnataka, India

t† Corresponding Author: Department of Physics, M S Ramaiah Institute of Technology Bangalore-560054, Karnataka, India; melavanki73@gmail.com 
Viallet equations by using the variation of Stokes shift with microscopic solvent dielectric constant $(\varepsilon)$ and refractive index (n). The excited dipole moments were also estimated by using the variation of Stokes shift with microscopic empirical solvent polarity parameter $\left(E_{T}^{N}\right)$ and the values are compared. It was estimated that dipole moments of the excited state were higher than those of the ground state of both the molecules. Further, the change in dipole moment $(\Delta \mu)$ were calculated both from solvatochromic shift method and on the basis of microscopic empirical solvent polarity $\operatorname{parameter}\left(E_{T}^{N}\right)$.

Keywords: Solvatochromic shift method, Ground state dipole moments, Excited state dipole moments, Thiophene carboxamido.

\section{Introduction}

In the last few years, thiophene-based materials which are semiconductor and fluorescent compounds have become a highly interdisciplinary field of research with diverse studies ranging from fabrication of electronic and optoelectronic devices to the selective detection of biosensors. These organic molecules are recognized to be important materials having novel electronic and photonic properties suitable for many technological applications [15]. It is also evident from the literature survey that thiophene such as substituted thiophene and condensed thiophene are interesting compounds being studied in medicine and they are reported to possess an array of useful biological and pharmacological activities like antibacterial, antifungal, antiviral, anticancerous, analgesic and anti-inflammatory activities. The synthesis, reactivity and conformational analysis of substituted and condensed thiophene have been extensively studied in recent years. They are important both as interesting models for structural investigation and also for biological screening. The effect of solvent on the absorption and fluorescence characteristics of organic compounds has been a subject of interesting investigation. Excitation of a molecule by photon causes a redistribution of charges leading to conformational changes in the excited state. This can result in an increase or decrease of dipole moment of the excited state as compared to 50 
ground state. The dipole moment of an electronically excited state of a molecule is an important property that provides information on the electronic and geometrical structure of the molecule in the short-lived state.

Knowledge of the excited state dipole moment of electronically excited molecules is quite useful in designing nonlinear materials, elucidating the nature of the excited states and in determining the course of a photochemical transformation. The electro optic methods such as electronic polarization of fluorescence, electricdichroism, microwave conductivity and stark splitting are generally considered to be very accurate, but their use is limited because they are considered equipment sensitive and the studies have been restricted to relatively very simple molecules. The solvatochromic method is based on the shift of absorption and fluorescence maxima in different solvents of varying polarity. Koutek has shown that under suitable conditions, the solvatochromic method yields fairly satisfactory results. Similar works were also reported by others [6-17]. In the present work, we report different solvent effect on the Photophysical properties such as Stokes shift which is useful for estimation of the ground and excited state dipole moments of two thiophene Carboxamidos by solvatochromic method based on absorption and fluorescence shift in various solvents. However, there are no reports available in literature on the determination of $\mu_{\mathrm{g}}$ and $\mu_{\mathrm{e}}$ values of these two biologically active thiophene Carboxamidos investigated. The theoretical ground state $\left(\mu_{\mathrm{g}}\right)$ dipole moments were estimated by Gaussian software using B3LYP/6-31g* method [18].

\section{Materials and Methods}

The solute molecules namely 2-(3', 4', 5' -trimethoxy phenyl) imino3-N-thylcarboxamido-4,5,-tetramethylenethiophene $(X)$ and $2\left(4^{\prime}-\mathrm{N}\right.$, $\mathrm{N}$ dimethylaminophenyl)imino 3(N-2'-methylphenylcarboxamido) 4,5,tetramethylenethiophene $(\mathrm{Y})$ were synthesized in our laborator y using standard methods [19-20]. The molecular structures of this thiophene Carboxamido are given in Fig. 1. The solvents used in the recent study namely acetonitrile (AN), dichloro ethane (DCE), Diethylether (DEE), Dimethylformamide (DMF), dimethylsulphoxi 
de (DMSO), heptane, hexane, isopropyl alcohol (IPA) and toluene (TL) for $\mathrm{X}$ and acetonitrile (AN), cyclohexane $(\mathrm{CH})$, diethyl ether (DEE),

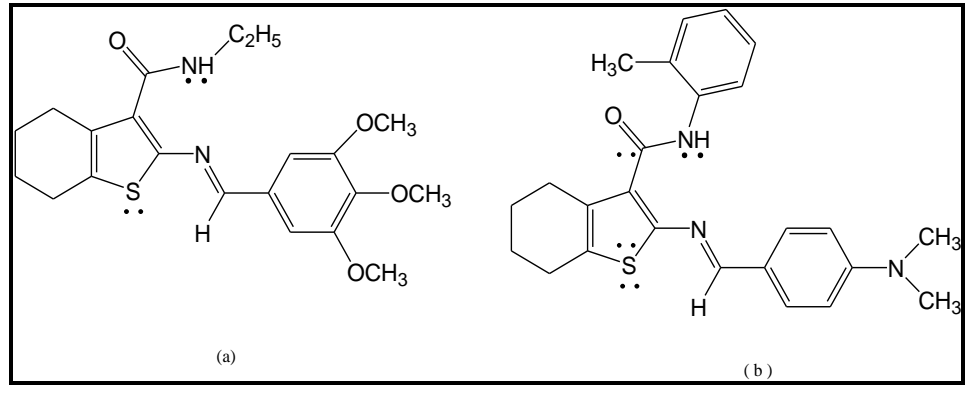

Fig. 1. The molecular structures of (a) X and (b) Y.

1,4-dioxane (DX), heptane, hexane, isopropyl alcohol-(IPA), tetrahydrofauran (THF) and toluene (TL) for $\mathrm{Y}$ were obtained from S-D-Fine Chemicals Ltd., India, and they were of spectroscopic grade. The required solutions were prepared at fixed concentration of solutes $1 \times 10^{-5} \mathrm{M}$ in each solvent. The absorption spectra were recorded using Hitachi 50-20 UV-Vis spectrophotometer. The fluorescence spectra were recorded using Hitachi F-2000 fluorescence spectrophotometer. All these measurements were carried out at room temperature.

\section{Theory}

\subsection{Determination of excited-state dipole moments}

The five independent equations were used for the estimation of excited state dipole moments of two thiophene carboxamido. They are as follows

Lippert's equation [21]:

$\overline{\vartheta_{\alpha}}-\overline{\vartheta_{f}}=m_{1} F_{1}(\varepsilon, n)+$ constant

Bakhshiev's equation [22]:

$\overline{\vartheta_{\alpha}}-\overline{\vartheta_{f}}=m_{\mathbf{2}} F_{\mathbf{2}}(\varepsilon, n)+$ constant 
Kawski-Chamma-Viallet's equation [23]:

$\frac{\overline{\vartheta_{a}}+\overline{\vartheta_{f}}}{2}=-m_{3} F_{a}(\epsilon, n)+$ constant

The expressions for $F_{1}(\varepsilon, n)$ [Lippert's polarity function], $F_{2}(\varepsilon, n)$, [Bakhshiev's polarity function] $\mathrm{F}_{3}(\varepsilon, \mathrm{n})$, [Kawski-Chamma-Viallet's polarity function] are given as

$$
\begin{aligned}
& F_{1}(\varepsilon, n)=\left[\frac{\varepsilon-1}{2 \varepsilon+1}-\frac{n^{2}-1}{2 n^{2}+1}\right] \\
& F_{2}(\varepsilon, n)=\left[\frac{\varepsilon-1}{\varepsilon+2}-\frac{n^{2}-1}{n^{2}+2}\right] \frac{\left(2 n^{2}+1\right)}{\left(n^{2}+2\right)} \\
& F_{3}(\varepsilon, n)=\frac{\left(2 n^{2}+1\right)}{2\left(n^{2}+2\right)}\left[\frac{\varepsilon-1}{\varepsilon+2}-\frac{n^{2}-1}{n^{2}+2}\right]+\frac{3\left(n^{4}-1\right)}{2\left(\left[n^{2}+2\right) \rrbracket^{2}\right.}
\end{aligned}
$$

Where $\bar{v}_{a}$ and $\bar{v}_{f}$ are absorption and fluorescence maxima wavelength in $\mathrm{cm}^{-1}$ respectively. The other symbols $\varepsilon$ and $\mathrm{n}$ are dielectric constant and refractive index respectively. From Eqs. (1)(3) it follows that $\left(\bar{v}_{a}-v_{f}\right)$ versus $\mathrm{F}_{1}(\varepsilon, \mathrm{n}),\left(\bar{v}_{a}-v_{f}\right)$ versus $\mathrm{F}_{2}(\varepsilon, \mathrm{n})$ and $\frac{\overline{v_{a}}+\bar{v}_{f}}{2}$ versus $\mathrm{F}_{3}(\varepsilon, \mathrm{n})$ should give linear graphs with slopes $m_{1}, m_{2}$ and $m_{3}$ respectively and are given as

$$
\begin{gathered}
m_{1}=\frac{2\left(\left[\mu_{g}-\mu_{g}\right) \rrbracket^{2}\right.}{h c a^{3}} \\
m_{2}=\frac{2\left(I \mu_{g}-\mu_{g}\right) \rrbracket^{2}}{h c a^{3}} \\
m_{a}=\frac{2\left(\mu_{\theta}^{2}-\mu_{g}^{2}\right)}{h c a^{3}}
\end{gathered}
$$

Where $\mu_{\mathrm{g}}$ and $\mu_{\mathrm{e}}$ are the ground and excited state dipole moments of the solute molecules. The symbols $h$ and c are Planck's constant and velocity of light in vacuum respectively; ' $a$ ' is the Onsager 
radius of the solute molecule. If the ground state and excited states are parallel, the following expressions are obtained on the basis of Eqs. (8) and (9)

$\mu_{g}=\frac{m_{z}-m_{z}}{2}\left[\frac{h c a^{3}}{2 m_{2}}\right]^{\frac{1}{2}}$

$\mu_{e}=\frac{m_{a}+m_{z}}{2}\left[\frac{h c a^{3}}{2 m_{2}}\right]^{\frac{1}{2}}$

and

$\mu_{\varepsilon}=\left[\frac{m_{\mathbf{z}}+m_{\mathbf{a}}}{m_{\mathbf{a}}-m_{\mathbf{z}}} \mu_{g}\right.$ for $\quad\left(m_{3}>m_{2}\right)$

\subsection{Molecular-microscopic solvent polarity parameter $\left(E_{T}^{N}\right)$}

The empirical polarity parameter $\left(E_{T}^{N}\right)$ proposed by Richards [7] gave towering results with solvatochromic shift of dipolar molecules. The results correlate better with microscopic solvent polarity parameter $\left(E_{T}^{N}\right)$ rather than the traditionally used bulk solvent polarity functions involving dielectric constant $(\varepsilon)$ and refractive index $(\mathrm{n})$. In $\left(E_{T}^{N}\right)$ the error estimation of the Onsager cavity radius has been minimized, it also includes intermolecular solute/solvent hydrogen bond donor/acceptor interactions along with solvent polarity. The theoretical basis for the correlation of the spectral band shift with $\left(E_{T}^{N}\right)$ was proposed by Richards and developed by Ravi et al. [24], according to Eq. (13):

$$
\begin{gathered}
\bar{v}_{a}-\bar{v}_{f}=11307.6\left[\left(\frac{\Delta \mu}{\Delta \mu_{\mathrm{B}}}\right)^{2}\left(\frac{\mathrm{a}_{\mathrm{B}}}{\mathrm{a}}\right)^{2}\right] \mathrm{E}_{\mathrm{T}}^{\mathrm{N}} \\
+ \text { Constant }
\end{gathered}
$$

where $\Delta \mu_{B}=9 \mathrm{D}$ and $\mathbf{a}_{\mathrm{B}}=6.2 \mathrm{~A}^{\circ}$ are the change in dipole moment on excitation and Onsager cavity radius respectively of a betaine dye, $\Delta \mu$ and ' $\mathbf{a}$ ' are the corresponding quantities for the solute molecule of interest. A dimensionless normalized scale $\left(E_{T}^{N}\right)$ was introduced in order to avoid the use of non SI unit $\mathrm{kcal} / \mathrm{mol}$ in $\mathrm{E}_{\mathrm{T}}{ }^{(30)}$ solvent polarity scale and is defined by Eq. (14), using water 
$\left[\left(E_{T}^{N}\right)=1\right]$ and tetramethylsilane $\left(\mathrm{TMS}=\left(E_{T}^{N}\right)=0\right)$ as extreme reference solvents.

$E_{T}^{N}=\frac{E_{T}(\text { Solvent })-E_{T}(\text { TMS })}{E_{T}(\text { Water })-E_{T}(\text { TMS })}=\frac{E_{T}(\text { Solvent })-30.7}{32.4}$

The change in dipole moment $(\Delta \mu)$ can be evaluated from the slope of the stokes shift versus $\left(E_{T}^{N}\right)$ plot and is given by Eq. (15)

$$
\Delta \mu=\left(\mu_{e}-\mu_{g}\right)=\sqrt{\frac{m X 81}{(6.2 / a)^{3} 11307.6}}
$$

Where ' $\mathrm{m}$ ' is the slope obtained from the plot of Stokes shift $\left(\overline{v_{a}}-v_{f}\right)$ versus microscopic solvent polarity $\left(E_{T}^{N}\right)$ using Eq. (13). For the computation, Gaussian software is used to calculate theoretical $\mu_{\mathrm{g}}$ using DFT.

\section{Results and discussion}

\subsection{Experimental determination of excited state $\left(\mu_{\mathrm{e}}\right)$ dipole moments of the molecules}

The typical absorption and fluorescence spectra of $X$ and $Y$ in isopropanol are as shown in Fig. 2 and Fig. 3 respectively. Solvent polarity function values $\mathrm{F}_{1}(\varepsilon, n), \mathrm{F}_{2}(\varepsilon, n), \mathrm{F}_{3}(\varepsilon, \mathrm{n})$ and microscopic solvent function $\left(E_{T}^{N}\right)$ for various solvents used in this report are presented in Table 1 and Table 2. The absorption and emission maxima wave numbers, Stokes shift and arithmetic mean of Stokes shift values (in $\mathrm{cm}^{-1}$ ) for both the molecules in different solvents are given in Table 1 and Table 2. Absorption and emission maxima wave numbers are calculated from wavelength maxima values. The large magnitude of Stokes shift indicates that the excited state geometry could be different from that of the ground state. The general observation is that there is an increase in the Stokes shift values with increasing solvent polarity which shows there is an increase in the dipole moment on excitation.

The Solvatochromic data can be used to identify the spectra, namely $\pi \rightarrow \pi^{*}, \mathrm{n} \rightarrow \mathrm{n}^{*}$, etc. The fluorescence emission peak 
undergoes a red shift, confirming a $\pi \rightarrow \pi^{*}$ transition. The shift of the fluorescence wavelengths towards longer wavelengths could be due to the marked difference between the excited state charge distribution in the solute and the ground state charge distribution resulting in a stronger interaction with polar solvents in the excited state.

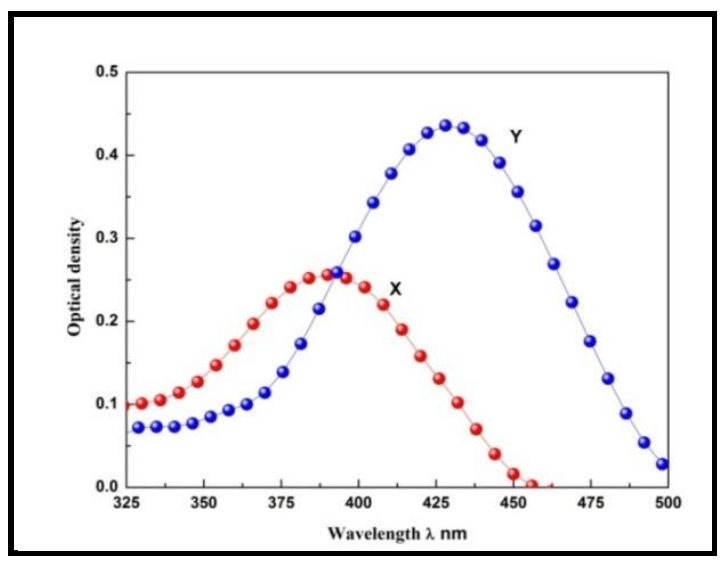

Fig. 2. Typical absorption spectra of $\mathrm{X}$ and $\mathrm{Y}$ in Isopropanol

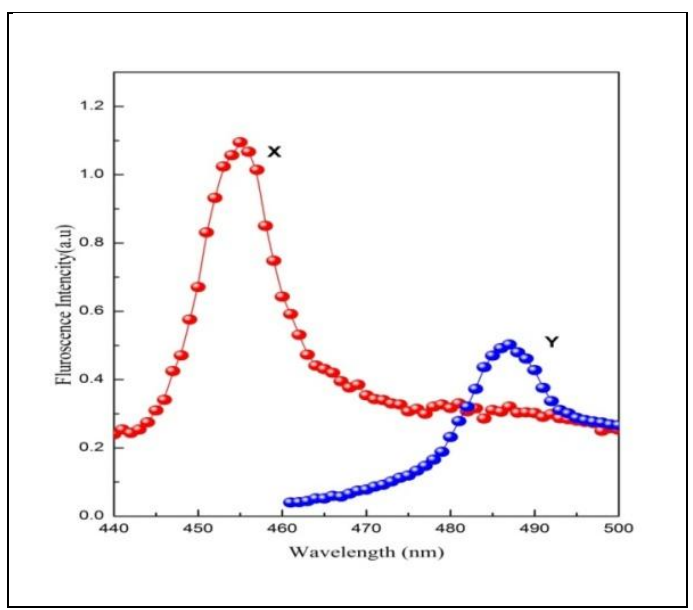

Fig. 3. Typical fluorescence spectra of $X$ and $Y$ in Isopropanol. 


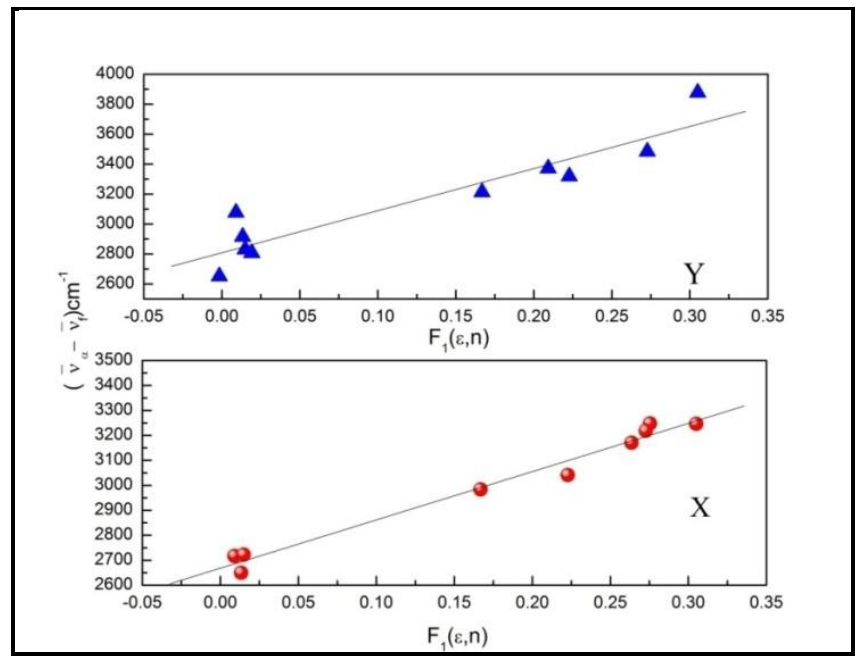

Fig. 4. The plots of $\left(\overline{v_{a}}-\overline{v_{f}}\right)$ vs $\mathrm{F}_{1}(\varepsilon, \mathrm{n})$ for $\mathrm{X}$ and $\mathrm{Y}$.

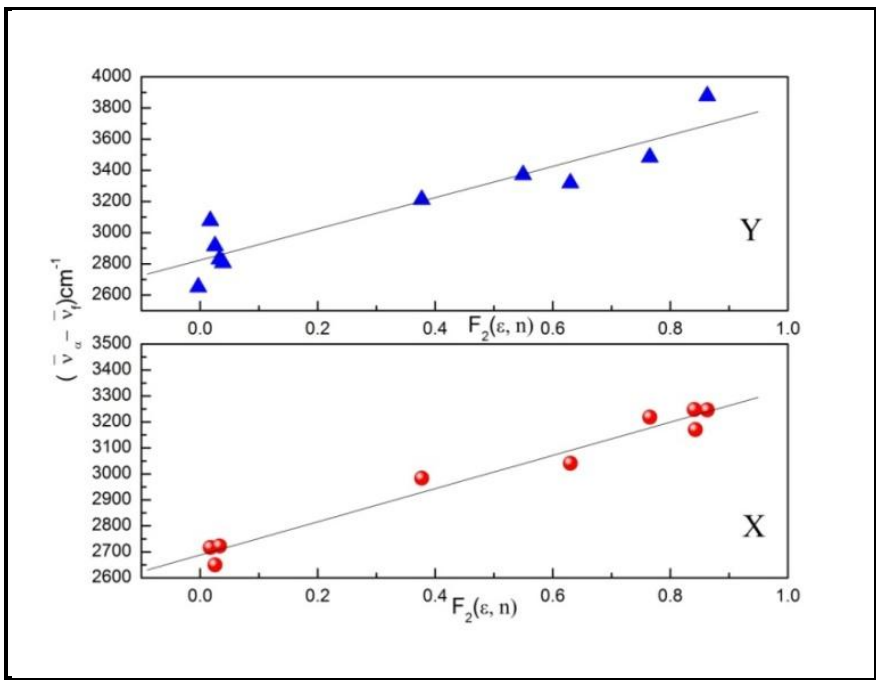

Fig. 5. The plots of $\left(v_{a}-v_{f}\right)$ vs $\mathrm{F}_{2}(\varepsilon, \mathrm{n})$ for $\mathrm{X}$ and $\mathrm{Y}$. 


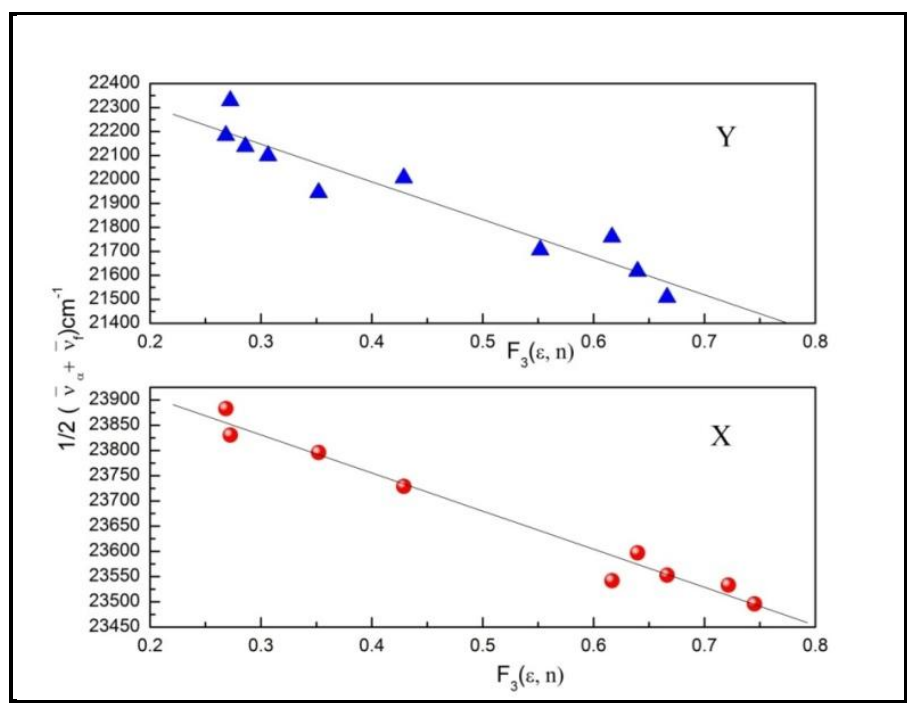

Fig. 6. The plots of $1 / 2\left(\bar{v}_{a}+v_{f}\right)$ vs $\mathrm{F}_{3}(\varepsilon, \mathrm{n})$ for $\mathrm{X}$ and $\mathrm{Y}$.

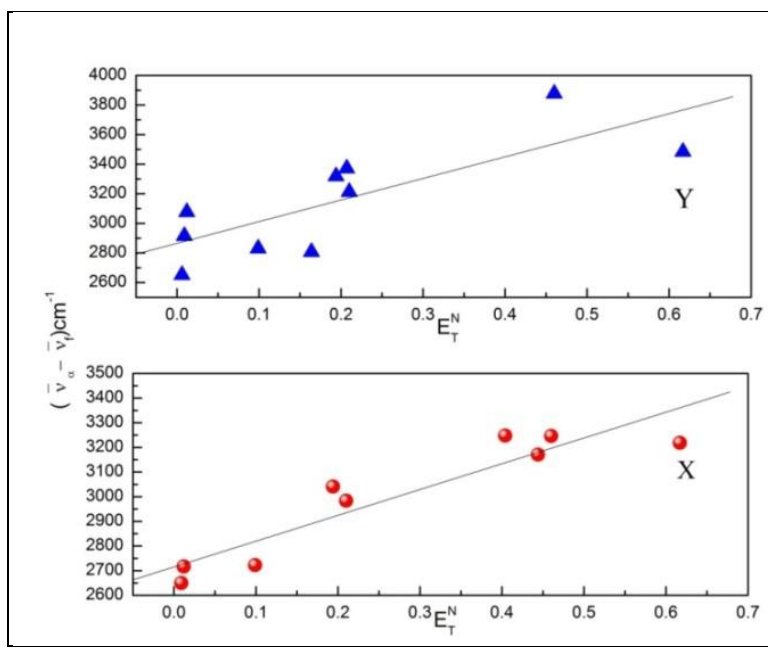

Fig. 7. The plots of $\left(\bar{v}_{a}-v_{f}\right)$ vs molecular- microscopic solvent polarity parameter $\left(E_{T}^{N}\right)$ for $\mathrm{X}$ and $\mathrm{Y}$. 


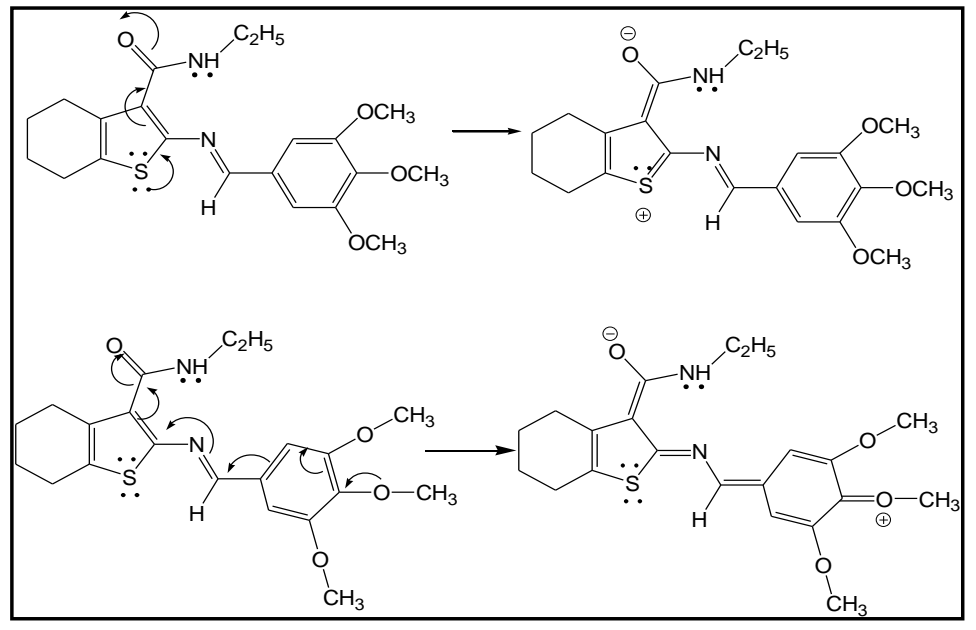

Fig. 8. Possible resonance structures of $X$.

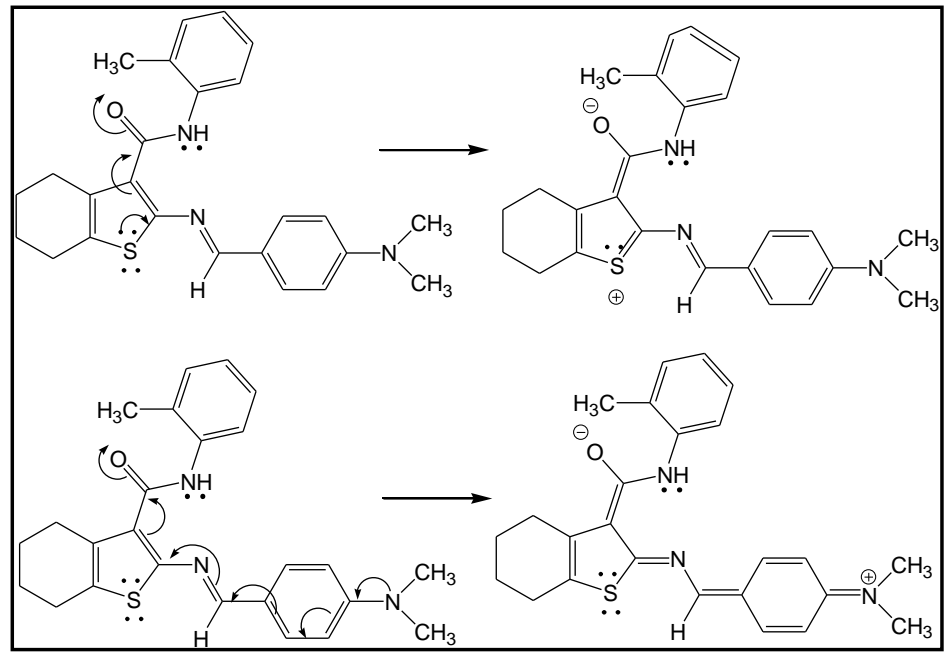

Fig. 9. Possible resonance structures of $Y$ 


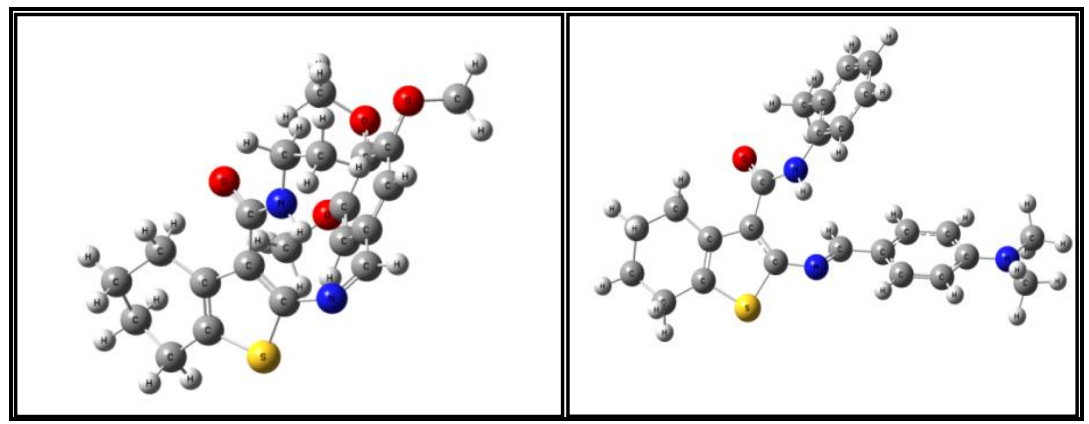

(a)

(b)

Fig. 10. Optimized geometry of (a) $X$ and (b) $Y$

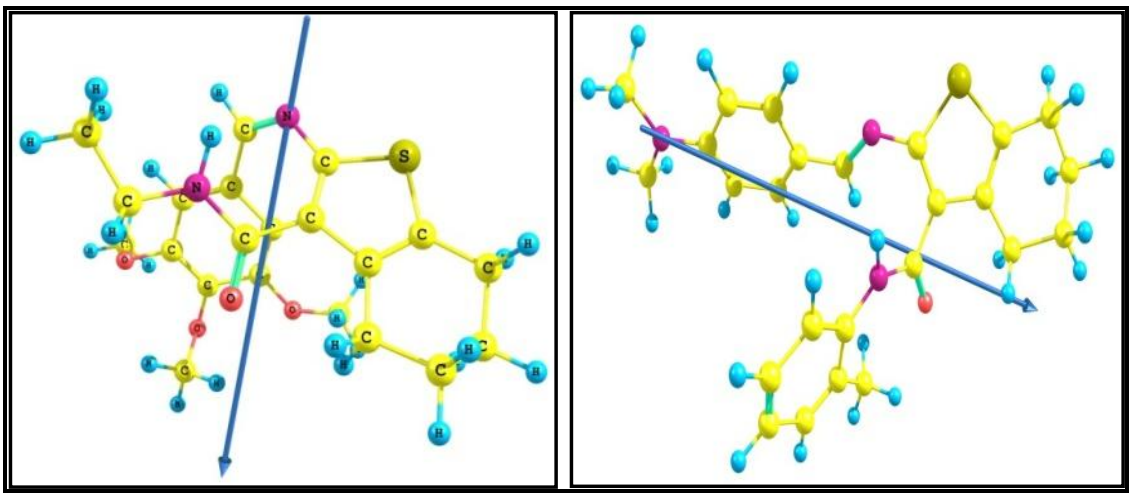

(a)

(b)

Fig. 11. Ground state optimized geometry of (a) X and (b) Y. The arrow indicates the direction of the dipole moment.

Fig. 4 to Fig. 7 show the graph of $\left(\bar{v}_{a}-v_{f}\right)$ versus $\mathrm{F}_{1}(\varepsilon, \mathrm{n}),\left(\bar{v}_{a}-\bar{v}_{f}\right)$ versus $\mathrm{F}_{2}(\varepsilon, \mathrm{n})$ and $\frac{v_{a}+v_{f}}{2}$ versus $\mathrm{F}_{3}(\varepsilon, \mathrm{n})$ from which slopes $\mathrm{m}_{1}, \mathrm{~m}_{2}$ and $\mathrm{m}_{3}$ are obtained respectively. The plot of $\left(\overline{v_{a}}-\overline{v_{f}}\right)$ versus $\left(E_{T}^{N}\right)$ will give the slope $\mathrm{m}$. The correlation co-efficient, slopes and number of data of the fitted lines are given in Table 3. Good correlation coefficient is obtained for all both the solutes. In most of the cases the correlation coefficients are larger than 0.900 and indicate a linearity for $\mathrm{m}, \mathrm{m}_{1}, \mathrm{~m}_{2}$ and $\mathrm{m}_{3}$ with selected number of Stokes shift data points. The ground state dipole moments $\left(\mu_{\mathrm{g}}\right)$ of 60 
the two molecules have been estimated by using Eq. (10) and are presented in Table 4. However, no other experimental data on $\mu_{\mathrm{g}}$ could be obtained from literature for comparison. The $\mu_{\mathrm{e}}$ values obtained from Eqs. (11) and (12) are given in Table 4. The ratio of $\mu_{\mathrm{e}}$ and $\mu_{\mathrm{g}}$ obtained from Eq. (12) and $\Delta \mu$ obtained from eq. (15) are presented in the Table 4 . It may be noted that discrepancies occur between the estimated values of $\mu_{\mathrm{e}}$ for both the molecules. These differences in the values of $\mu_{\mathrm{e}}$ may be, in part, due to the various assumptions and simplifications made in the use of different Solvatochromic methods.

The values of Onsager cavity radii of the $X$ and $Y$ molecules were calculated by molecular volumes and Parachor [25] and are listed in Table 4 . The theoretically calculated ( $a b$ intio calculations using DFT) values are presented in Table 4 . The difference in the ground state dipole moment is due to the necessity of knowing the radius of the solute molecule in Eq. (10) as compared theoretical values obtained from $a b$ initio calculations using DFT.

The dipole moments of both the molecules studied here are higher in the excited state compared to ground state. This is explained in terms of possible resonance structures as shown in Fig. 8 and Fig. 9. The dipole moments of $\mathrm{X}$ and $\mathrm{Y}$ increases twice on excitation. This change in dipole moment on excitation can be explained in terms of nature of emitting state or intermolecular charge transfer. Further large change in dipole moment on excitation suggests that excited state is twisted intermolecular charge transfer 
Table 1: Solvatochromic data of $X$ along with the calculated values of polarity functions.

\begin{tabular}{|c|c|c|c|c|c|c|c|c|c|c|}
\hline Solvents & $\begin{array}{c}\overline{v_{a}} \\
\left(\mathbf{c m}^{-1}\right)\end{array}$ & $\begin{array}{c}\overline{v_{f}} \\
\left(\mathbf{c m}^{-1}\right)\end{array}$ & $\begin{array}{c}\Delta v=\left(\overline{v_{a}}-\overline{v_{f}}\right) \\
\left(\mathbf{c m}^{-1}\right)\end{array}$ & $\begin{array}{c}1 / 2\left(\overline{v_{a}-v_{f}}\right) \\
\left(\mathbf{c m}^{-1}\right)\end{array}$ & $\varepsilon$ & $\mathbf{n}$ & $\mathbf{F}_{1}(\varepsilon, \mathbf{n})^{\mathrm{a}}$ & $\mathbf{F}_{2}(\varepsilon, \mathbf{n})^{\mathbf{b}}$ & $\mathbf{F}_{3}(\varepsilon, \mathbf{n})^{\mathrm{c}}$ & $\left(E_{T}^{N}\right)^{\mathrm{d}}$ \\
\hline Acetonitrile & 25176.23 & 21929.82 & 3246.40 & 23553.02 & 37.50 & 1.345 & 0.3050 & 0.8628 & 0.6663 & 0.460 \\
\hline DCE & 25062.65 & 22021.58 & 3041.07 & 23542.11 & 10.70 & 1.445 & 0.2227 & 0.6300 & 0.6165 & 0.194 \\
\hline DEE & 25220.68 & 22237.04 & 2983.63 & 23728.86 & 4.34 & 1.353 & 0.1668 & 0.3772 & 0.4289 & 0.210 \\
\hline DMF & 25157.23 & 21909.16 & 3248.06 & 23533.19 & 39.00 & 1.431 & 0.2753 & 0.8408 & 0.7215 & 0.404 \\
\hline DMSO & 25081.51 & 21910.60 & 3170.91 & 23496.05 & 48.00 & 1.479 & 0.2636 & 0.8425 & 0.7450 & 0.444 \\
\hline Heptane & 25188.91 & 22471.91 & 2717.00 & 23830.41 & 2.00 & 1.388 & 0.0090 & 0.0173 & 0.2724 & 0.012 \\
\hline Hexane & 25207.96 & 22558.08 & 2649.87 & 23883.02 & 2.00 & 1.376 & 0.0133 & 0.0252 & 0.2684 & 0.009 \\
\hline Isopropanol & 25201.61 & 21982.85 & 3218.75 & 23597.23 & 18.30 & 1.378 & 0.2727 & 0.7650 & 0.6396 & 0.617 \\
\hline Toluene & 25157.23 & 22434.60 & 2722.62 & 23795.91 & 2.40 & 1.497 & 0.0150 & 0.0330 & 0.3519 & 0.099 \\
\hline
\end{tabular}

a Lippert's polarity function

b Bakhshiev's polarity function

c Kawski-Chamma-Viallet's polarity function

$\mathrm{d}$ Microscopic solvent polarity function. 
Table 2: Solvatochromic data of $Y$ along with the calculated values of polarity functions

\begin{tabular}{|c|c|c|c|c|c|c|c|c|c|c|}
\hline Solvents & $\begin{array}{c}\overline{v_{a}} \\
\left(\mathbf{c m}^{-1}\right)\end{array}$ & $\begin{array}{c}\overline{v_{f}} \\
\left(\mathbf{c m}^{-1}\right)\end{array}$ & $\begin{aligned} \Delta v= & \left(\bar{v}_{a}-v_{f}\right) \\
& \left(\mathbf{c m}^{-1}\right)\end{aligned}$ & $\begin{array}{c}1 / 2\left(\overline{v_{a}-v_{f}}\right) \\
\left(\mathbf{c m}^{-1}\right)\end{array}$ & $\varepsilon$ & $\mathbf{N}$ & $\mathbf{F}_{1}(\varepsilon, \mathbf{n})^{\mathrm{a}}$ & $\mathbf{F}_{2}(\varepsilon, n)^{\mathbf{b}}$ & $\mathbf{F}_{3}(\varepsilon, n)^{\mathbf{c}}$ & $\left(E_{T}^{N}\right)^{\mathrm{d}}$ \\
\hline Acetonitrile & 23446.65 & 19569.47 & 3877.18 & 21508.06 & 37.50 & 1.345 & 0.3050 & 0.86280 & 0.6663 & 0.460 \\
\hline Cyclohexane & 23463.16 & 20811.65 & 2651.50 & 22137.4 & 2.02 & 1.426 & -0.0015 & -0.00313 & 0.2859 & 0.006 \\
\hline DCE & 23419.20 & 20100.50 & 3318.70 & 21759.85 & 10.70 & 1.445 & 0.2227 & 0.63000 & 0.6165 & 0.194 \\
\hline DEE & 23612.75 & 20399.83 & 3212.91 & 22006.29 & 4.34 & 1.353 & 0.1668 & 0.37720 & 0.4289 & 0.210 \\
\hline 1,4-Dioxane & 23501.76 & 20695.36 & 2806.39 & 22098.56 & 2.20 & 1.423 & 0.0192 & 0.03890 & 0.3064 & 0.164 \\
\hline Heptane & 23866.34 & 20790.02 & 3076.32 & 22328.18 & 2.00 & 1.388 & 0.0090 & 0.01734 & 0.2724 & 0.012 \\
\hline Hexane & 23640.66 & 20725.38 & 2915.27 & 22183.02 & 2.00 & 1.376 & 0.0133 & 0.02525 & 0.2684 & 0.009 \\
\hline Isopropanol & 23364.48 & 19868.86 & 3483.77 & 21616.67 & 18.30 & 1.378 & 0.2727 & 0.76500 & 0.6396 & 0.617 \\
\hline THF & 23391.81 & 20020.00 & 3371.79 & 21705.91 & 7.60 & 1.408 & 0.2092 & 0.54954 & 0.5519 & 0.207 \\
\hline Toluene & 23364.48 & 20533.88 & 2830.60 & 21944.97 & 2.40 & 1.497 & 0.0150 & 0.03304 & 0.3519 & 0.099 \\
\hline
\end{tabular}

a Lippert's polarity function

b Bakhshiev's polarity function

c Kawski-Chamma-Viallet's polarity function

d Microscopic solvent polarity function. 


\begin{tabular}{|l|c|c|c|c|}
\hline Correlations & Compound & Slope & Correlation & $\begin{array}{l}\text { Number of } \\
\text { data }\end{array}$ \\
\hline Lippert Correlation & $\mathrm{X}$ & 1934.19 & 0.989 & 9 \\
\hline & $\mathrm{Y}$ & 2811.329 & 0.933 & 10 \\
\hline $\begin{array}{l}\text { Bakhshiev's } \\
\text { correlation }\end{array}$ & $\mathrm{X}$ & 639.057 & 0.985 & 9 \\
\hline & $\mathrm{Y}$ & 1002.185 & 0.934 & 10 \\
\hline $\begin{array}{l}\text { Kawski-Chamma- } \\
\text { Viallet's } \\
\text { correlation }\end{array}$ & $\mathrm{X}$ & 754.928 & 0.986 & 9 \\
\hline & $\mathrm{Y}$ & 1571.769 & 0.954 & 10 \\
\hline correlation & $\mathrm{X}$ & 1046.01 & 0.927 & 9 \\
\cline { 2 - 5 } & $\mathrm{Y}$ & 1509.943 & 0.8 & 10 \\
\hline
\end{tabular}

Table 3: Statistical treatment of the correlations of the spectral shifts of $\mathrm{X}$ and $\mathrm{Y}$

\begin{tabular}{|c|c|c|c|c|c|c|c|c|c|}
\hline Compound & $\begin{array}{c}\text { Radius } \\
\mathrm{a}^{\prime}\left(\mathrm{A}^{\mathrm{o}}\right)\end{array}$ & $\begin{array}{c}\mu_{\mathrm{g}}{ }^{\mathrm{a}} \\
(\mathrm{D})\end{array}$ & $\begin{array}{c}\mu_{\mathrm{g}}^{\mathrm{b}} \\
(\mathrm{D})\end{array}$ & $\begin{array}{c}\mu_{\mathrm{e}}^{\mathrm{c}} \\
(\mathrm{D})\end{array}$ & $\begin{array}{c}\mu_{\mathrm{e}}^{\mathrm{d}} \\
(\mathrm{D})\end{array}$ & $\begin{array}{c}\mu_{\mathrm{e}}{ }^{\mathrm{e}} \\
(\mathrm{D})\end{array}$ & $\begin{array}{c}\Delta \mu^{\mathrm{f}} \\
(\mathrm{D})\end{array}$ & $\begin{array}{c}\Delta \mu^{\mathrm{g}} \\
(\mathrm{D})\end{array}$ & $\left(\mu_{\mathrm{e}} / \mu_{\mathrm{g}}\right)^{\mathrm{h}}$ \\
\hline $\mathrm{X}$ & 4.452 & 0.8571 & 0.215 & 2.583 & 4.334 & 1.880 & 2.368 & 1.665 & 12.140 \\
\hline $\mathrm{Y}$ & 4.521 & 4.736 & 0.863 & 3.897 & 5.946 & 2.905 & 3.034 & 2.042 & 4.518 \\
\hline
\end{tabular}

Table 4: Ground and excited state dipole moments of $\mathrm{X}$ and $\mathrm{Y}$

Debye $(\mathrm{D})=3.33564 \times 10^{-30} \mathrm{~cm}=10^{-18} \mathrm{esu} \mathrm{cm}$.

a Calculated by Gaussian Software.

$\mathrm{b}$ The ground states dipole moments calculated using Eq. 10.

c The excited states dipole moments calculated using Eq. 11.

d The experimental excited state dipole moments calculated from Lippert's equation.

e The experimental excited state dipole moments calculated from microscopic solvent polarity correlation.

f The change in dipole moments for $\mu_{\mathrm{e}}{ }^{\mathrm{c}}$ and $\mu_{\mathrm{g}}{ }^{\mathrm{b}}$

$\mathrm{g}$ The change in dipole moments calculated from Eq. 15.

$\mathrm{h}$ The ratio of excited state and ground state dipole moments values calculated using Eq.12. 
(TICT) in nature. Thus presence of a large TICT and increase in planarity on excitation render the molecule more polar (as compared to ground state) giving rise to a large change in the dipole. In literature one may find that large number of investigators have used solvatochromic shift method to estimate ground and excited state dipole moments. In literature there is a dearth of data on $\mu_{\mathrm{g}}$ and $\mu_{\mathrm{e}}$ for the molecules used in the present study. Therefore we have not made any comparison.

\subsection{Theoretical determination of ground state $\left(\mu_{\mathrm{g}}\right)$ dipole moments}

The primary task for the computational work was to determine the optimized geometry of the compound. The entire calculations were performed at DFT/B3LYP level on a Pentium IV/2.8 GHz personal computer using Gaussian 03W program package, invoking gradient geometry optimization [18]. The input geometry of $X$ and $Y$ molecules has been first optimized without any constraint in the potential energy surfaces at DFT/6-31g* theory/basis set for $\mathrm{C}, \mathrm{N}$ and $\mathrm{H}$ atoms. The molecular structure of the title molecules in the ground state were optimized by a DFT method using B3LYP functional combined with $6-31 \mathrm{~g}^{*}$ basis set. The optimized geometry of the title molecules is given in Fig. 10.

Dipole moment shows the molecular charge distribution and is given as a vector in three dimensions. Therefore, it can be used as a descriptor to depict the charge movement across the molecule. Direction of the dipole moment vector in a molecule depends on the centers of positive and negative charges. Dipole moments are strictly determined for neutral molecules. The ground state dipole moments are calculated using DFT/6-31g* theory/basis set and are compared with experimental values. The optimized directions of the dipole moments are shown in Fig. 11.

\section{Conclusion}

We have estimated and compared the dipole moments of two molecules $X$ and $Y$ in the ground and excited states as a function of the solute-solvent interactions by Solvatochromic shift method. It 
can be seen that the dipole moments of $X$ and $Y$ are significantly higher in the excited state than in the ground state. The dipole moments of excited states range between 2.58 to 7.97D depending on the compounds. It may be noted that the measured values of $\mu_{\mathrm{g}}$ and $\mu_{\mathrm{e}}$ for $\mathrm{X}$ and $\mathrm{Y}$ differ from each other. This may be attributed to the structural difference between the molecules. Also Eq. (12) can be used to estimate the values of excited state dipole moments by pre knowledge of the value of the ground state dipole moment without the necessity of knowing Onsager radius of the solute. To our knowledge this is the first report on the dipole moments of these molecules and would be of great help in many fields as mentioned in introduction.

\section{Acknowledgements}

We greatly acknowledge Supercomputer Education and Research Center Indian Institute of Science, Bangalore for providing computation calculation facility (DFT). All the authors gratefully acknowledge the useful discussions had with Prof Siva Umapathy, Department of Inorganic and Physical Chemistry, Indian Institute of Science, Bangalore.

\section{References}

[1] K. K. Rothatgi-Mukherjee, Fundamental of Photochemistry, Wiley Easten Ltd., New Delhi, India, 1986.

[2] J. R. Lackowicz, Principles of Fluorescence Spectroscopy, Plenum Press New York, 1983.

[3] J. R. Sheats and P. F. Barbara, "Molecular Materials in electronic and optoelectronic devices," Acc. Chem. Res., vol. 32, p. 191, 1999.

[4] K. H. Drexhage in: F. P. Schafer, Structure and Properties of Laser Dyes, Topics in Applied Physics, Springer-Verlag, Berlin, p. 143, 1973.

[5] D. Binder, C. R. Noe, W. Holzer and B. Rosenworth, "Thiophen als Strukturelement physiologisch aktiver Substanzen, 12. Mitt. Thiophenanaloga antiviraler Chalkone," Arch. de Pharm. vol. 318, p. 48, 1985. http://dx.doi.org/10.1002/ardp.19853180111.

[6] G. Karminshi-Aamola and M. Bajc, "Synthesis of (5-Styryl-2-thienyl)phenylacrylic Acids," Heterocycles, vol. 23, p. 1497, 1985. http:// dx.doi.org/10.3987/R-1985-06-1497.

[7] C. Richards, Solvents and Solvent Effects in Organic Chemistry, $\mathrm{VCH}$, New York, 1991. 
[8] B. Koutek, "Dipole moments in excited state. Statistical investigation of methods employing solvatochromism," Collect. Czech. Chem. Commun., vol. 43, p. 2368, 1978. http://dx.doi.org/ 10.1135/ cccc19782368.

[9] N. R. Patil, R. M. Melavanki, S. B. Kapatkar, N. H. Ayachit and J. Saravanan, "Solvent Effect on Absorption and Fluorescence Spectra of Three Biologically Active Carboxamides $\left(C_{1}, C_{2}\right.$ and $\left.C_{3}\right)$. Estimation of Ground and Excited State Dipole Moment from Solvatochromic Method Using Solvent Polarity Parameters", J. Fluoresc., vol. 21, p. 1213, 2011. http://dx.doi.org/ 10.1007/s10895-010-0800-4.

[10]R. M. Melavanki, N. R. Patil, S. B. Kapatkar, N. H. Ayachit, S. Umapathy, J Thipperudrappa and A R Nataraju, "Solvent effect on the spectroscopic properties of 6MAMC and 7MAMC," J. Mol. Liquids, vol. 158, p. 105, 2011. http://dx.doi.org/10.1016/j.molliq.2010.11.002.

[11] R. M. Melavanki, H. D. Patil, S. Umapathy and J. S. Kadadevaramath, "Solvatochromic Effect on the Photophysical Properties of Two Coumarins," J. Fluoresc., vol. 22, p. 137, 2012. http://dx.doi.org/ 10.1007/s10895-011-0939-7.

[12]J. J. Aaron, M. D. Gaye, C. Parkanyi, N. S. Cho and L. Von Szentpaly, "Experimental and theoretical dipole moments of purines in their ground and lowest excited singlet states," J. Mol. Struct., vol. 156, p. 119, 1987. http://dx.doi.org/10.1016/0022-2860(87)85046-9.

[13]C. Parkanyi, M. R. Stem-Beren, O. R. Martinez, J. J. Aaron, M. B. MacNair and A. F. Arietta, "Solvatochromic correlations and groundand excited-state dipole moments of curcuminoid dyes," Spectrochim. Acta Part A. vol. 60, p. 1805, 2004. http://dx.doi.org/ 10.1016/j.saa.2003.07.013.

[14] Kawski, B. Kuklinski and P. Bojarski, "Thermochromic Absorption, Fluorescence Band Shifts and Dipole Moments of BADAN and ACRYLODAN," Z. Naturforsch, vol. 57A, pp. 716, 2002. http:/ /dx.doi.org/0932-0784 / 02 / 0800-0716.

[15]K. Fukui, T. Yonezawa and H. Shingu, "A Molecular Orbital Theory of Reactivity in Aromatic Hydrocarbons," J. Chem. Phys., vol. 20, p. 722, 1952. http://dx.doi.org/10.1063/1.1700523.

[16] L. Bilot and A. Kawski, "Theorie des Einflusses von Lösungsmitteln auf die Elektronenspektren der Moleküle," Z. Naturforsch, vol. 17A, p. 621, 1962.

[17] Kawski, "Untersuchungenn zum zwischenmolekularen Energieübergang in Fluoreszierenden Lösungen," Z. Naturforsch, vol. 18A, p. 961, 1963.

[18] M. J. Frisch, G. W. Trucks and H. B. Schlegel, "Gaussian, Revision B. Gaussian Inc"., Pittsburg, 2003, 
[19] K. Gewald, E. Schinke and H. Botcher, "Heterocyclen aus $\mathrm{CH}$-aciden Nitrilen, VIII. 2-Amino-thiophene aus methylenaktiven Nitrilen, Carbonylverbindungen und Schwefel," Chem. Ber. vol. 99, p. 94, 1966. http://dx.doi.org/10.1002/cber.19660990116.

[20]S. Mohan and J. Saravanan, "Synthesis, Characterization and Antibacterial Activity of Some Schiff Bases of 2-Amino-3-(N-Tolyl Carboxamido)-4,5,6,7-Tetrahydro Benzo(b)Thiophenes," Asian J. Chem. vol. 15, p. 67, 2003. http:/ /www.asianjournalofchemistry.co.in/ User/ViewFreeArticle.aspx?ArticleID=15_1_14.

[21]E. Lippert, "Dipolmoment und elektronstrukturen von angeregten molekülen," Z. Naturforsch., vol. 10A, p. 541, 1955.

[22] N. G. Bakshiev, "Universal intermolecular interactions and their effect on the position of the electronic spectra of molecules in two component solutions," Opt. Spectosk. (USSR), vol. 16, p. 821, 1964.

[23] Chamma and P. Viallet, "Determination du moment dipolaire d'une molecule dans un etat excité singulet: application á l'indole, au benzimidazole et á l'indazole," C. R. Acad. Sci. Paris, Ser., vol. C270, p. 1901, 1970.

[24] M. Ravi, T. Soujanya, A. Samanta and T. P. Radhakrishnan, "Excitedstate dipole moments of some Coumarin dyes from a solvatochromic method using the solvent polarity parameter, $E^{\mathrm{N}} \mathrm{T}^{\prime \prime} \mathrm{J}$. Chem. Soc. Faraday. Trans., vol. 91, p. 2739, 1995. http://dx.doi.org/ 10.1039/ FT9959102739.

[25]J. T. Edward, "Molecular volumes and Parachor", Chem, Ind. London, p. $774,1956$. 